\title{
Analysis of a thermal system through remote laboratories
}

\author{
Iván Santana, Luis Hernández \\ Dpto. de Automática y Sistemas Computacionales, \\ Universidad Central Marta Abreu de Las Villas, \\ Santa Clara, Cuba, \\ ching@uclv.edu.cu
}

\author{
Manuel Ferre, Enrique Pinto, José M. Cogollor \\ Centro de Automática y Robótica - CAR UPM - CSIC, \\ ETSI Industriales, Madrid, España, \\ m.ferre@upm.es
}

\begin{abstract}
This paper describes the experiences using remote laboratories for thorough analysis of a thermal system, including disturbances. Remote laboratories for education in subjects of control, is a common resorted method, used by universities. This method is applied to offer a flexible service in schedules so as to obtain greater and better results of available resources. Remote laboratories have been used for controlling physical devices remotely. Furthermore, remote labs have been used for transfer function identification of real equipment. Nevertheless, remote analyses of disturbances have not been done. The aim of this contribution is thereby to apply the experience of remote laboratories in the study of disturbances. Some experiments are carried out to demonstrate the effectiveness in using remote laboratories for complete analysis of a thermal system. Considering the remote access to thermal system, "Sistema de Laboratorios a Distancia" (SLD) was used.

Keywords- remote experiment; remote laboratories; education of control
\end{abstract}

\section{INTRODUCTION}

Teaching activity of technical subjects in engineering education cannot disregard doing experiments. The contact with the real world, such as handling real instruments that process real signals, is the only way to complete the theoretical part of education and provide students with the skills that enable them to deal with real problems successfully. Unfortunately, hands-on laboratories have high costs associated with the required equipment, space, and maintenance staff. These costs increase even more in areas where quality of education also calls for a large variety of laboratory equipment and experiments, such as robotics, control, mechatronics engineering, etc [1]. Another important limitation of hands-on practices is the high number of students. The use of information technology offers new opportunities in order to reduce these constraints. Remote laboratories can provide remote access to experiments and can allow learners to have access to experiments with less restrictions on time and location, providing the necessary guidance and assuring safe and secure operations for both equipment and staff [2].

Remote laboratories are widely used in the education of engineering, especially control engineering [3-10]. A Webbased control laboratory for experimentation on a nonlinear multiple-input-multiple-output (MIMO) system: the three-tank plant, which is introduced in [11]. Using this application, automation technical students can learn many fundamental aspects of control processes in a practical way. In [12], [13] an experimental mechatronic system and validation of the control design by remote experiments at Maribor University is presented. This system has been used in some E-courses of mechatronics. Networked Control System Laboratory (NCSLab) is a remote laboratory that aims at integrating various experiment devices located globally and offering various experiment services for users scattered around the world [14], [15].

In previous works, "Sistema de Laboratorios a Distancia" (SLD) created by the department of Automatic and Computational Systems of the Universidad Central "Marta Abreu" de Las Villas (UCLV) in collaboration with the Universidad Politécnica de Madrid (UPM) was presented [1618]. SLD is a remote laboratory whose main objective is to allow users to learn how to adjust predefined controllers and to design their own controllers in order to test them in real devices through the Internet.

Remote laboratories have been used for the remote control and for transfer function identification of real equipment. Nevertheless, the remote analyses of disturbances have not been tackled. One of the limitations that remote laboratories have in the area of control engineering is the impossibility to make analysis of the effects of disturbances. Majority of the scale models do not permit to implement disturbances on the study system. Others allow but only manually, such as the thermal system.

An important subject of control engineering is the analysis of disturbances. These undesired signals are present in the majority of real systems, which is why it is necessary to study the effect that they generate and how to compensate them.

This paper is focused on the use of remote laboratories for a complete analysis of a thermal system, including the study of disturbances. All academic activities described in this work are associated with Regulación Automática I subject. This subject is taught in the sixth semester for students of Industrial Engineering, major in Control Engineering or Electrical Engineering. The mentioned students have previously taken a course focused on modeling and design of continuous-time systems on their fifth semester. Both courses are taught by the Department of Control Engineering, Electronic Engineering and Computers Science at the Escuela Técnica Superior de Ingenieros Industriales of the UPM.

The paper is organized as follows. Section II describes the "Regulación Automática I" course (Control Engineering I) 
TABLE I. DISTRIBUTION OF THE STUDENT WORK ACCORDING TO THE PLANNED ACTIVITIES DURING THE SEMESTER

\begin{tabular}{|c|c|c|c|c|c|c|}
\hline Activity & $\begin{array}{l}\text { Time in class } \\
\text { room/laboratory }\end{array}$ & $\begin{array}{l}\text { Time out of class } \\
\text { room/laboratory }\end{array}$ & $\begin{array}{l}\text { Work factor for } \\
\text { studying }\end{array}$ & Study Time & $\begin{array}{c}\text { Total time effort by } \\
\text { the student }\end{array}$ & ECTS \\
\hline Lectures & 20 & - & 2 & 40 & 60 & 2,00 \\
\hline Problem solving & 10 & - & 2 & 20 & 30 & $\mathbf{1 , 0 0}$ \\
\hline $\begin{array}{l}\text { Works done in the laboratory } \\
\text { being physically present }\end{array}$ & 6 & - & 1 & 6 & 12 & $\mathbf{0 , 4 0}$ \\
\hline Works done remotely & - & 3 & 1 & 3 & 6 & $\mathbf{0 , 2 0}$ \\
\hline Control project & 4 & - & 5 & 20 & 24 & $\mathbf{0 , 8 0}$ \\
\hline Tutorial & - & 4 & - & - & 4 & $\mathbf{0 , 1 3}$ \\
\hline $\begin{array}{l}\text { Seminars by experts from the } \\
\text { industry }\end{array}$ & - & 2 & 2 & 2 & 4 & $\mathbf{0 , 1 3}$ \\
\hline \multirow[t]{2}{*}{ Exams } & - & 4 & - & - & 4 & $\mathbf{0 , 1 3}$ \\
\hline & 40 & 13 & - & 91 & 144 & 4,80 \\
\hline
\end{tabular}

organized according to the ECTS methodology. Section III describes the thermal system. This section explains the modifications that have been done to the thermal system in order to accept remote disturbances. Section IV focuses on the remote practices for the thermal system, including the analysis of disturbances. Section $\mathrm{V}$ describes remote practice results. Section VI shows the results obtained in the last three courses. Statistics about the devoted time by students is summarized according to the questionnaires filled out by students at the course end. Furthermore, qualification evolution achieved in these years is described. Finally, section VII summarizes the main results of the study.

\section{SUBJECT ORGANIZATION}

Activities involved in this course include the following: lectures, problem solving, laboratory work done while physically present in the lab or remotely, a control project, tutorials, participation in seminars led by industry experts and exams. All of these activities are clearly defined in terms of their content and the time invested by the professor and students. The work factor for students is defined as the relationship between the time devoted by the professor to teaching and the time required by the student to acquire all necessary knowledge and skills relevant to the topic. This work factor is a key factor to properly define the complexity of each activity. The total work factor amounts around 144 hours, which is equivalent to 4.8 ECTS [19].

Table I summarizes the time effort distribution to each activity and its corresponding work factor. The goal of each activity is described as follows:

- Lectures focus on teaching the theoretical contents of each topic. Classes are organized in two hour sessions, topics are mainly taught using slides. All contents are included in a book prepared by the professors, and a complementary bibliography is also recommended to the students. A common classroom is used for this activity.
- Problem solving is also taught in the classroom but the goal is to focus on students' interest by presenting interesting control engineering problems that address the topic being taught.

- Works in the laboratory focus on interacting with physical systems that are modeled by the corresponding transfer function. The goal is to define a control scheme and a regulator that achieve the required behavior. Students have to complete a selfassessment test on the theoretical content related to the experimental work. These tests are performed prior to the experiments.

- Control project is an activity that integrates several topics within a broader subject. Students have to identify a system, propose a transfer function, and design a control scheme and the corresponding controller.

- Tutorials, seminars and evaluations are also included in the course plan.

Student activities outside of the class room include a combination of self-assessment tests and work in the laboratory that is performed while physically present in the laboratory and remotely. Self-assessment tests are completed at the end of each topic to check that students have acquired the necessary knowledge prior to carrying out the experimental work. This activity was performed using AulaWeb [20], developed at the UPM.

In [17] the authors defend the methodology of suitable combination of hands-on experiments, remote practices and activities of self-assessment applied in the Regulación Automática I subject. The aim of combining present and remote works in the laboratory is to take advantage of both scenarios.

The laboratory of practices where hand-on activities are carried out is formed by eight positions, each equipped with a computer, a data acquisition card (AD622 of Humusoft) and 


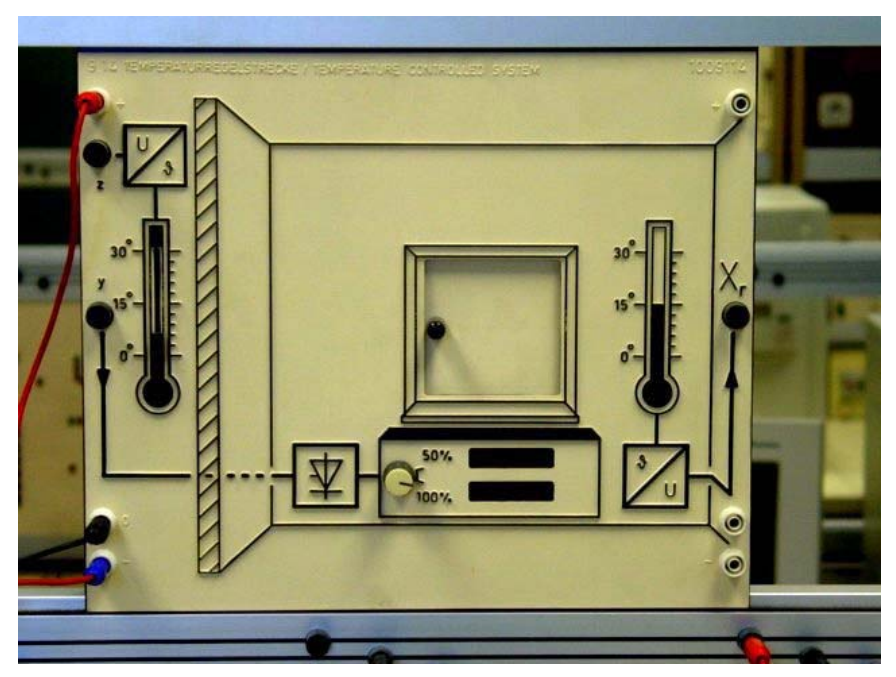

Figure 1. Thermal model

two scale models, a thermal system and DC motors; both are used by students being physically present or remotely.

The subject matters are dedicated to modeling and analyzing discrete systems, as well as studying feedback systems, with emphasis in the controller design. One of the chapters is about methods of system identification using algorithms based on square minimums as well as ident tool of MATLAB.

The ending activities of the subject are focused on studying the methods that allow minimizing disturbances. A hand-on practice focused on the identification of DC motors is carried out. The identification of the thermal system is assigned as homework and done remotely using SLD. This work allows students to perform identification of the thermal system disturbances through SLD.

\section{THE THERMAL SYSTEM}

The thermal system available in the laboratory is shown in Fig. 1. With this system, the student will be able to carry out practices in open loop (analysis and identification of the system) and practices in closed loop (temperature control).

The thermal system is a SISO model (Single Input Single Output). The process variable of the systems is the temperature at a room. The system has the following signals:

- Manipulated variable Y: Input signal of the system. It provides the excitation signal for the thermal system, which is an analogical signal from 0 to 10 volts. The power of the thermal system can be varied by a switch of two positions: 50 or $100 \%$.

- Process variable Xr: Output signal of the system. It provides the value of the temperature at interior of the room. It is an analogical signal from 0 to 10 volts equivalent to a variation of 0 to $30^{\circ} \mathrm{C}$.

The thermal system has two disturbances: opening/closing of window and variation of the exterior temperature of the room. The disturbance window is manually operated causing a

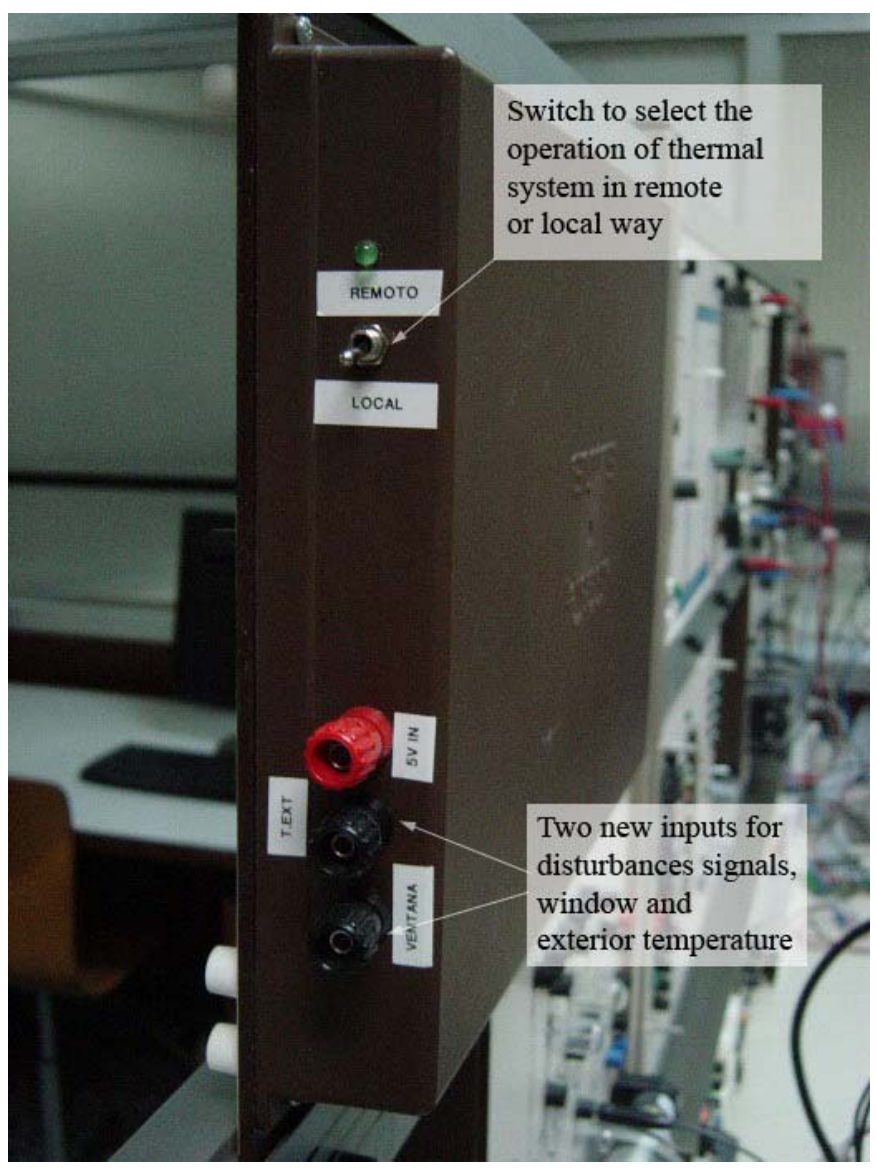

Figure 2. Lateral view of the modified thermal scale model

reduction of the internal temperature when being open. The position of the window cannot be determined.

The disturbance of the exterior temperature is generated through a linear potentiometer that allows variations of temperature between 0 to $30^{\circ} \mathrm{C}$. This disturbance is measurable and indicated as $\mathrm{Z}$ in the frontal. This analogical signal provides a continuous voltage between 0 to 10 volts equivalent to variation of 0 to $30^{\circ} \mathrm{C}$.

The scale model needs an external power source of \pm 15 volts continuous for its operation.

Experiments that students can develop using a thermal system with data acquisition card are as follows:

- Studying of the behavior of the system in open loop.

- Identifying the system to obtain $\mathrm{Xr} / \mathrm{Y}$ model.

- Studying and analyzing disturbances of the system.

- Studying the behavior of the system in closed loop.

- Controlling internal temperature of the room with PID controller.

- Controlling internal temperature of the room with anticipatory regulators to compensate disturbances. 
In previous works, some remote practices for thermal system have been developed [16-18]. The analysis of disturbance has been not done in a remote way because the window can only be manually operated. Knowing how to act on the disturbances remotely is the difficulty the thermal scale model has. The thermal system has been internally modified with the purpose of acting on each disturbance through a data acquisition card.

\section{A. Thermal system modification in order to accept remote disturbances}

A switch on the lateral side of the scale model has been placed in order to start it. This switch allows selecting the use of scale model on local or remote way. In the local position, the scale model works normally. The window is manually opened and closed. In order to increase or reduce exterior temperature, the potentiometer of the frontal panel must be used. In the remote position the disturbances were disconnected so they cannot be manually operated by students. For remote operation two additional inputs have been placed (called window and ext. temp.) in the lateral side of the scale model as Fig. 2 show.

The first input (window) is connected to a digital output of the data acquisition card so that generating a digital signal 0 or 1, the same effect takes place upon opening/closing the window on the scale model.

The second input (ext. temp.) is connected to an analogical output of the data acquisition card providing a continuous voltage of the same variation as produced by the frontal potentiometer on the scale model. With the voltage generated in this output, it is acceded to the internal electronic of the scale model in the same point as the frontal potentiometer.

All the necessary electronics has been mounted within the scale model on a circuit board with an external power source of \pm 5 volts continuous for its operation.

With the modifications made on the thermal scale model, all the experiments enumerated previously can be carried out in remote way.

\section{REMOTE PRACTICES FOR THE THERMAL SYSTEM}

SLD was used taking remote access to thermal system into account.

The SLD allows two types of practices: one with a predefined controller and another with a controller created by the user [18].

- Predefined controller practices: This type of practices can also be called parametric practices. The user only has access to modify certain parameters, like the gains of PID controller, the step amplitude, etc.

- Controller created by the user: The user has the possibility of changing some blocks of the system model, like the controller block, the references block, etc. After downloading a Simulink model, the user modifies the file using the Simulink blocks. Some modifications in other advanced parameters, like the runtime, sample time, etc, can also be done.
ENSAYO DE UN SISTEMA TÉRMICO

A continuación se muestra el esquema para ensayar un sistema térmico en bucle abierto

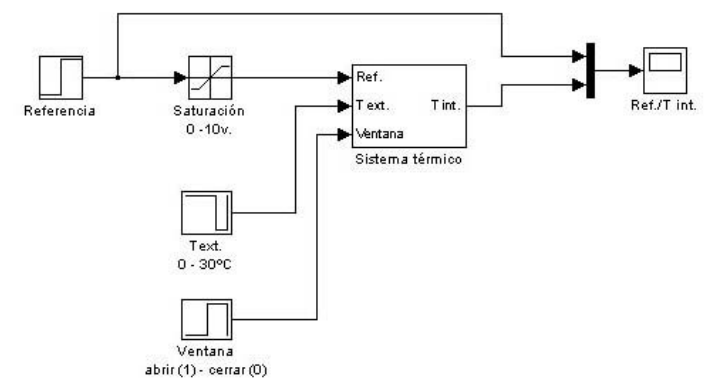

El sistema consta de una entrada para fijar la referencia de temperatura y una salida para medir la temperatura interior de un recinto. Ambas señales son analógicas en el rango a dos perturbaciones independientes: abrir/cerrar ventana, subir/bajar temperatura del exterior.

En esta actividad se podrá identificar la función de transferencia del sistema térmico y analizar el efecto que producen las perturbaciones sobre la temperatura interior de recinto. En estos

HAY ESTACIONES LIBRES. EL RESULTADO DEL ENSAYO SE MOSTRARÁ A LOS 150 SEGUNDOS APROXIMADAMENTE.

ANÁLISIS DE UN SISTEMA TÉRMICO EN BUCLE ÁBIERTO:

\begin{tabular}{|c|c|c|c|}
\hline $\begin{array}{l}\text { Sin perturbación: } \\
\text { Valor de la Referencia: }\end{array}$ & 5 & ] volts & 1 \\
\hline \multicolumn{4}{|l|}{$O$ con perturbación ventana: } \\
\hline Abrir la ventana a los: & 80 & \multirow{2}{*}{$\begin{array}{l}\text { volts } \\
\text { segundos } \\
\text { segundos }\end{array}$} & \multirow{2}{*}{2} \\
\hline Cerrar la ventana a los: & 120 & & \\
\hline \multicolumn{4}{|c|}{ O Con perturbación temperatura exterior: } \\
\hline Valor de la Referencia: & 5 & \multirow{4}{*}{$\begin{array}{l}\text { volts } \\
\text { segundos } \\
\text { grados Celcius }(0-30) \\
\text { segundos }\end{array}$} & \multirow{4}{*}{3} \\
\hline Elevar la temp. ext, a los: & 80 & & \\
\hline Elevar la temp. ext en: & 7 & & \\
\hline Descender la temp. ext. a los: & 120 & & \\
\hline
\end{tabular}

Ensayar

Figure 3. Web page of remote practice Test of the thermal system

In [18] a remote practice for PID controller adjustment for the temperature control in internal room of the thermal system has been exposed. In addition, a practice with controller user defined was designed [17]. With this practice, the students test other algorithms of control and design their own controllers using MATLAB/Simulink.

For the analysis of the thermal system, a remote practice has been developed. The designed remote experiment, called "Test of the thermal system", allows making the complete study of a thermal system. Moreover, it also permits analyzing the signals disturbances window and exterior temperature. For the remote experiment, an appropriate Web page was constructed (Fig. 3).

Test of a thermal system is a parametric practice that allows the student to focus their learning on the study of thermal systems. The students can choose between analyzing the thermal system without disturbance, with window disturbance or with exterior temperature disturbance. The input signal is a step that can change its amplitude.

1. This section allows analyzing the performance of the thermal system with step input. The student can change the step amplitude, no greater than 10 . The result of carrying out the practice is a Web page and a data 
TABLE II. DESCRIPTION OF EXPERIMENTS DEVELOPED

\begin{tabular}{|c|c|c|c|}
\hline \multirow{2}{*}{$\begin{array}{l}\text { Number of } \\
\text { Experiments }\end{array}$} & \multicolumn{3}{|c|}{ Input and disturbances description } \\
\hline & Input & Window disturbance & Exterior temperature disturbance \\
\hline Test 1 & Step signal with amplitude of 5 volts & - & - \\
\hline Test 2 & Step signal with amplitude of 5 volts & $\begin{array}{l}\text { Open window at } 80 \text { seconds and closed } \\
\text { window at } 120 \text { seconds }\end{array}$ & - \\
\hline Test 3 & Step signal with amplitude of 5 volts & $x^{-1}$ & $\begin{array}{l}\text { Increase exterior temperature in } 7^{\circ} \mathrm{C} \text { at } 80 \\
\text { seconds and reduce exterior temperature at } \\
120 \text { seconds }\end{array}$ \\
\hline
\end{tabular}

RESULTS (V/SEG)

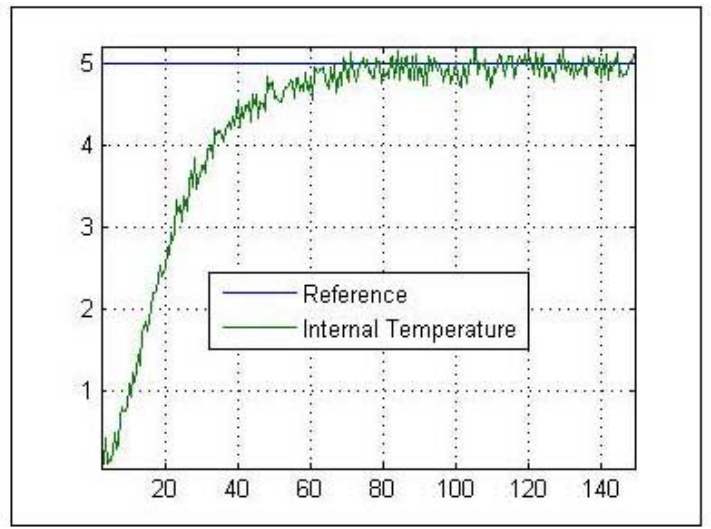

Figure 4. Thermal system response without disturbance

\section{RESULTS ( $/$ /SEG)}

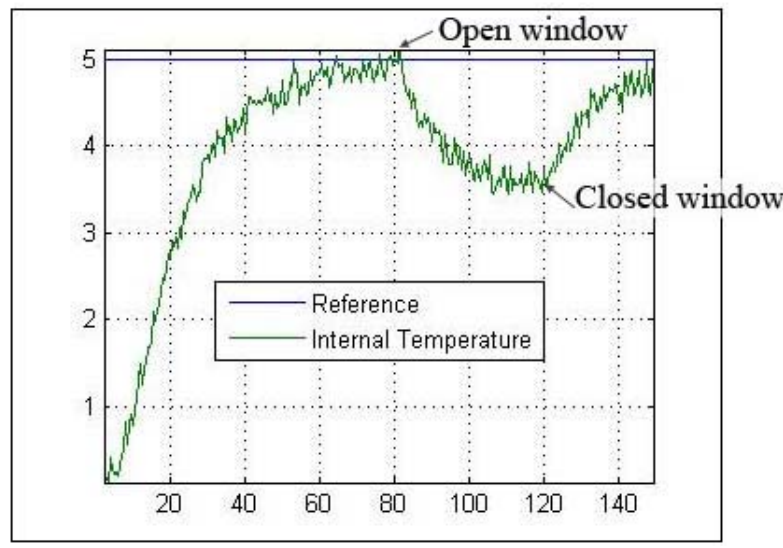

Figure 5. Thermal system response with window disturbance

vector. Using this data vector, students can identify the transfer function of the thermal system.

2. In this section, students can analyze the performance of the thermal system with window disturbance. Students can change the step amplitude, no greater than 10, like previous sections. Furthermore, students can fit when opening and closing the window to bring about the disturbance. The result of carrying out the practice is also a Web page and a data vector. With this data vector, students can identify the transfer function of the window disturbance. 120 seconds
RESULTS ( $V / S E G)$

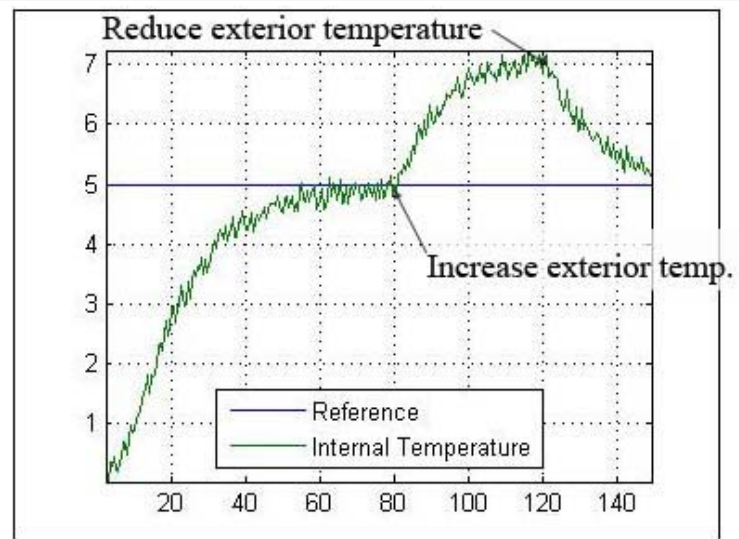

Figure 6. Thermal system response with exterior temperature disturbance

3. This last section allows the analysis of the thermal system performance with exterior temperature disturbance. The students, besides changing the step amplitude, can vary the time in which it is desired to increase or to reduce the exterior temperature. With the data vector, students can identify the transfer function of the exterior temperature disturbance.

After selecting the type of experiment to carry out, the button "Ensayar" is clicked obtaining the results of the execution in the thermal system.

\section{REMOTE PRACTICE RESULT}

To analyze the performance of the thermal system, three different experimental tests were developed as shown in Table II. In the developed experiments one of the disturbances is only applied every time. The input signal is applied in the three experiments, reason of wait that the system has become stabilized to apply the disturbance.

The obtained results of first to third remote experiments are shown in Fig. 4 to 6 respectively.

From the developed experiments it is possible to identify the transfer function of the thermal system. The window disturbance and exterior temperature disturbance can also be identified. With these transfer functions, students can design controllers for thermal system and minimize the disturbances effects. These controllers can be tested using SLD through Internet. 


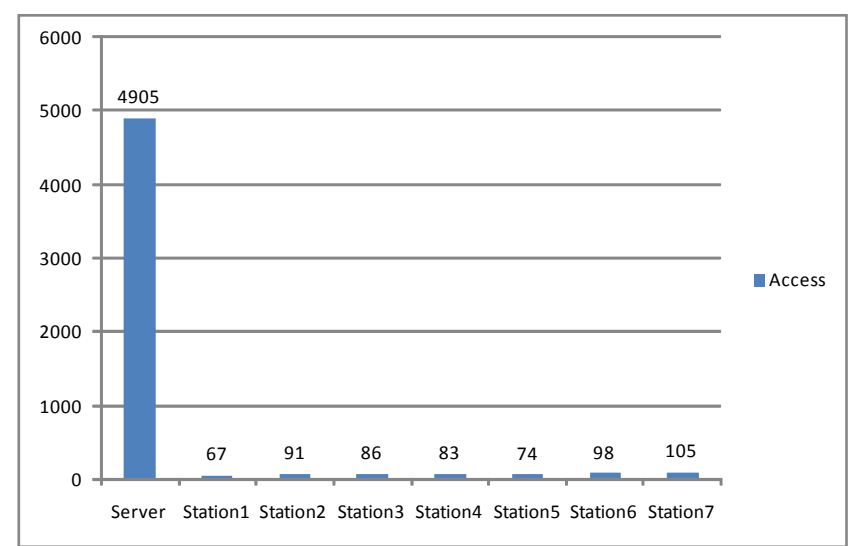

Figure 7. Students access to remote systems

\section{RESULTS OBTAINED IN THE SUBJECT}

The results obtained at the last courses using SLD were positive. Students were very motivated with using SLD for remote practices. Several studies have been done to evaluate the impact in the teaching of control engineering using the methodology that combines hands-on and remote laboratories. Among the techniques used include expert groups, the participant's observation during the execution of laboratory practices and surveys. These good results have motivated the extension and development of new practices for the SLD.

\section{A. Remote acces}

Throughout the last course, over five thousand accesses to the SLD were registered, mainly between April and June. All virtual remote practices and the integrated project were carried out in the Web server [17]; and real remote practices in seven positions of the laboratory. Figure 7 shows the access to SLD along the last course.

There was a greater amount of accesses to the Web server because it hosts the activities of the integrated project. Each student did more than thirty accesses to the SLD to make the three parts of the integrated project as average. This reflected the workload of student for this activity.

The SLD has the possibility of executing several practices simultaneously in different stations. In case all stations were occupied, a queue by station would be created. The results of the accesses showed no collisions occurred during access and time delay has never been greater than acceptable time in executing the practice.

\section{B. Students' Opinions}

A survey on the subject was carried out. Items considering this survey include:

1. The real practices in the laboratory were very important for my formation

2. The amount of real practices in the laboratory was acceptable

3. Hands-on practices have been useful for my learning
4. Remote practices have been useful for my learning

5. The combination of hands-on with remote activities have verified my skills and my knowledge

6. How do you rate the performance of the SLD as a tool for remote access to real physical devices?

7. How do you value remote practices developed through SLD?

8. I would recommend SLD to other students

Survey results, in a Likert scale from 1 to 5 (strongly disagree to strongly agree), have behaved as follows (Figure 8). A sample of 170 students from two last courses, 2009-2010, 2010-2011, was chosen. In the first academic year where SLD was used 2008-2009, only an exploratory survey was been done.

\section{CONCLUSIONS}

ECTS methodology has demonstrated to be a good tool to properly quantify students' work. However, several activities have been done during the course in order to distribute students' effort accordingly. This justifies the development of new practical activities through remote laboratories, in our case, SLD.

Students' opinion has been positive. The survey indicates that they have worked harder, with higher motivation and more consistency than doing it without a regular test. In addition, professors have confirmed that students who have answered the test increased their learning and became better prepared in doing practical activities.

The combination of hands-on and remote laboratories allows students to know the equipments when they go to the laboratory. It also lets students have an effective use when accessing remotely.

SLD allows students to access laboratory equipments remotely in a similar way when they are physically present. The friendly use of the Web application is due to the transparent integration of software (MATLAB and Simulink) typically used in the laboratory with the SLD. This has permitted to design controllers for the equipment in the

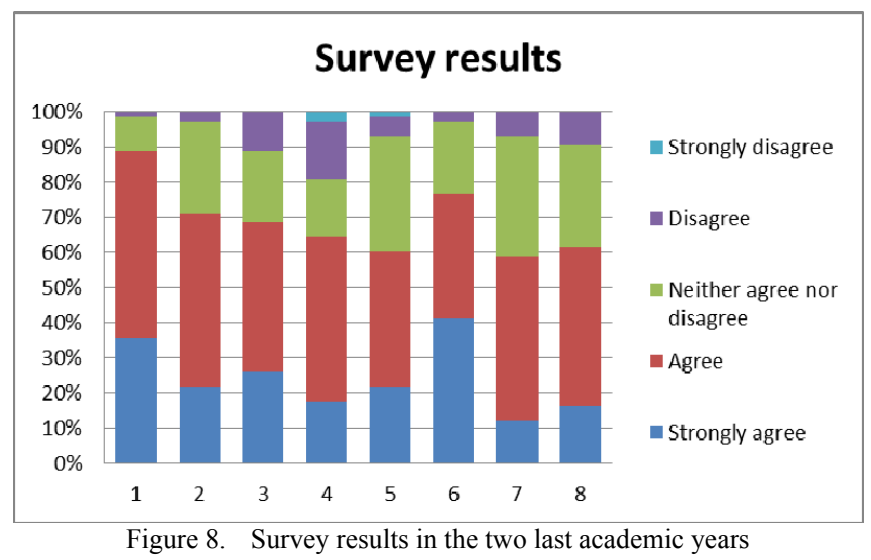


laboratory and run controllers in real time. Moreover, a complete analysis of the thermal system, including the disturbances, can currently be done. So, the aim of this contribution is thereby to apply the experience of remote laboratories in the study of disturbances. Students value positively the whole availability of the equipment, ready to be used in order to check different controllers and identify systems. It permits them to obtain data and evaluate system performance in a small period of time.

The main benefit obtained to date is the reinforcing of the students' learning process when using the combination of hands-on and remote practices. This is derived from the fact that the real hours allow them to familiarize and manipulate the physical equipment directly, whereas remote working hours permit them to test different algorithms and techniques from control without the schedule restrictions. This methodology increases the practical activities. In addition, students devote more time to the subject during the semester and this effort is rewarded in the final mark.

\section{ACKNOWLEDGMENT}

This work is partially funded by the Vice-Rectorate of Ordenación Académica y Planificación Estratégica of the Universidad Politécnica de Madrid. The authors would like to acknowledge the participation and contribution of "Regulación Automática I" students in these three last courses at the Escuela Técnica Superior de Ingenieros Industriales of UPM.

\section{REFERENCES}

[1] L. Gomes and S. Bogosyan, "Current Trends in Remote Laboratories," Industrial Electronics, IEEE Transactions on, vol. 56, pp. 4744-4756, 2009.

[2] J. J. Rodriguez-Andina, et al., "Current Trends in Industrial Electronics Education," Industrial Electronics, IEEE Transactions on, vol. 57, pp. 3245-3252, 2010.

[3] C. A. Jara, et al., "EJS+EjsRL: An interactive tool for industrial robots simulation, Computer Vision and remote operation," Robotics and Autonomous Systems, vol. 59, pp. 389-401, 2011.

[4] E. Fabregas, et al., "Developing a remote laboratory for engineering education," Computers \& Education, vol. 57, pp. 16861697, 2011.

[5] C. Ferrater-Simon, et al., "A Remote Laboratory Platform for Electrical Drive Control Using Programmable Logic Controllers," Education, IEEE Transactions on, vol. 52, pp. 425-435, 2009.

[6] M. Cooper and J. M. M. Ferreira, "Remote Laboratories Extending Access to Science and Engineering Curricular," Learning Technologies, IEEE Transactions on, vol. 2, pp. 342-353, 2009.
[7] E. Sancristobal, et al., "Remote labs as learning services in the educational arena," in IEEE Global Engineering Education Conference (EDUCON), Amman, 2011, pp. 1189 - 1194.

[8] C. A. Jara, et al., "Real-time collaboration of virtual laboratories through the Internet," Computers \& Education, vol. 52, pp. 126-140, 2009.

[9] R. Puerto, et al., "Remote control laboratory via Internet using Matlab and Simulink," Computer Applications in Engineering Education, vol. 18, pp. 694-702, 2010.

[10] H. Vargas, et al., "Docencia en Automática: Aplicación de las TIC a la realización de actividades prácticas a través de Internet a la realización de actividades prácticas a través de Internet," Revista Iberoamericana de Automática e Informática Industrial (RIAI), vol. 7, pp. 35-45, 2010.

[11] R. Dormido, et al., "Development of a Web-Based Control Laboratory for Automation Technicians: The Three-Tank System," Education, IEEE Transactions on, vol. 51, pp. 35-44, 2008.

[12] A. Rojko, et al., "Power Engineering and Motion Control Web Laboratory: Design, Implementation, and Evaluation of Mechatronics Course," Industrial Electronics, IEEE Transactions on, vol. 57, pp. 33433354,2010

[13] A. Rojko, et al., "Mechatronics E-course for regular students and adults: Realization and comparison of efficiency," in IEEE Education Engineering (EDUCON), Madrid, 2010, pp. 959 - 966.

[14] Q. Yuliang, et al., "Design and implementation of a serviceoriented web-based control laboratory," in Systems, Man and Cybernetics, 2009. SMC 2009. IEEE International Conference on, 2009, pp. $4645-4650$.

[15] Q. Yuliang, et al., "NCSLab: A Web-Based Global-Scale Control Laboratory With Rich Interactive Features," Industrial Electronics, IEEE Transactions on, vol. 57, pp. 3253-3265, 2010.

[16] I. Santana, et al., "Design of servo system in state space using Distance Laboratory System (DLS)," in International Conference on Computer Supported Education (CSEDU 2009), Lisboa, Portugal, 2009.

[17] I. Santana, et al., "Distance Practices in Subjects of Automatic Control," in IEEE Engineering Education 2010 - The Future of Global Learning in Engineering Education (EDUCON), Madrid, 2010, pp. 967 972.

[18] I. Santana, et al., "Aplicación del Sistema de Laboratorios a Distancia en Asignaturas de Regulación Automática.," Revista Iberoamericana de Informática Industrial (RIAII), vol. 7, pp. 46-53, 2010 .

[19] M. Ferre, et al., "Nueva metodología docente de las asignaturas de Regulación Automática I y Control por Computador," in I Jornadas de Innovación Educativa de la Escuela Politécnica Superior de Zamora, Zamora, 2006, pp. 183-186.

[20] A. García-Beltrán and R. Martínez., "Web assisted assessment in computer programming learning using AulaWeb," International Journal of Engineering Education, vol. 22, pp. 1063-1069, 2006. 